\title{
Accumulation of 1-Aminocyclopropane-1-carboxylic acid (ACC) in Petunia Pollen is Associated with Expression of a Pollen-specific ACC Synthase Late in Development
}

\author{
Jon T. Lindstrom, ${ }^{1}$ Chih-Hsien Lei, Michelle L. Jones, ${ }^{2}$ and William R. Woodson ${ }^{3}$ \\ Department of Horticulture and Landscape Architecture, Purdue University, West Lafayette, IN 47907-1165
}

AdDitional INDEX wORDs. ethylene, gene expression, Petunia hybrida, pollen, pollen-specific promoter

\begin{abstract}
Mature pollen from Petunia hybrida contains significant levels of 1-aminocyclopropane-1-carboxylic acid (ACC), and this ACC is thought to play a role in pollination-induced ethylene by the pistil. We investigated the developmental accumulation of ACC in anthers and pollen. The level of ACC in anthers was very low until the day before anthesis, at which time it increased 100-fold. A 1.1-kb partial ACC synthase cDNA clone (pPHACS2) was amplified from total RNA isolated from mature anthers by reverse transcriptase, followed by polymerase chain reaction using oligonucleotide primers synthesized to conserved amino acid sequences in ACC synthases. The expression of pPHACS2 mRNA during anther development was correlated with the accumulation of ACC and was localized to the pollen grain. The pPHACS2 cDNA was used to identify the $P H-A C S 2$ gene from a library of genomic DNA fragments from Petunia hybrida. PH-ACS2 encoded an ACC synthase transcript of four exons interrupted by three introns. The ACC synthase protein encoded by the $\mathrm{PH}-\mathrm{ACS} 2$ gene shared $>80 \%$ homology with ACC synthases from tomato $(L E-A C S 3)$ and potato (ST-ACS1a). A chimeric $P H$-ACS2 promoter- $\beta$-glucuronidase (GUS) gene was used to transform petunia and transgenic plants were analyzed for GUS activity. GUS staining was localized to mature pollen grains and was not detected in other tissues. Despite similarities to $L E$ - $A C S 3$, we did not detect GUS activity under conditions of anaerobic stress or in response to auxin. A series of 5-prime-flanking DNA deletions revealed that sequences within the $P H$ - $A C S 2$ promoter were responsible for pollen-specific expression.
\end{abstract}

The plant hormone ethylene is synthesized from the amino acid ACC by the enzyme ACC oxidase (Fluhr and Mattoo, 1996; Kende, 1993). In most plant tissues, the rate of ethylene production is determined by the activity of ACC synthase, which converts $S$ adenosylmethionine to ACC (Kende, 1993). Genes encoding ACC synthase and ACC oxidase have been identified in a number of plant species, and in both cases are represented by multigene families that exhibit differential patterns of expression (Fluhr and Mattoo, 1996; Lasserre et al., 1996; Liang et al., 1992; 1996; Rottmann et al., 1991; Tang et al., 1993, 1994). ACC synthase genes have been shown to be regulated by auxin, ethylene, wounding, ozone, anaerobiosis, $\mathrm{Li}$, senescence, cycloheximide, and/or ripening (Kende, 1993; Fluhr and Mattoo, 1996). Expression studies have revealed that the induction of ACC synthase activity is most often the result of increased accumulation of ACC synthase mRNAs (Kende, 1993; Zarembinski and Theologis, 1994). However, in some situations the activity of ACC synthase has been shown to be regulated at the posttranslational level (Felix et al., 1991).

In many flowers, pollination stimulates ethylene production and accelerates corolla senescence (Jones and Woodson, 1997; Larsen et al., 1995; Stead, 1992). This pollination-induced ethylene production is first detectable from the stigma/style and is thought to coordinate postpollination development, including co-

Received for publication 5 June 1998. Accepted for publication 4 Sept. 1998. Publication number 15860 of the Purdue University Office of Agricultural Research Programs. This study was supported by grants from the U.S. Department of Agriculture/National Research Initiative Competitive Grants Program and the American Floral Endowment. The cost of publishing this paper was defrayed in part by the payment of page charges. Under postal regulations, this paper therefore must be hereby marked advertisement solely to indicate this fact.

${ }^{1}$ Current address: Department of Horticulture, University of Arkansas, Fayetteville, AR 72701.

${ }^{2}$ Current address: Department of Horticulture and Landscape Architecture, Colorado State University, Fort Collins, CO 80523-1173.

${ }^{3}$ To whom reprint requests should be addressed; e-mail: wrw@ hort.purdue.edu.

J. Amer. Soc. Hort. SCI. 124(2):145-151. 1999. rolla senescence (Nichols et al., 1983; Pech et al., 1987; Whitehead et al., 1983). The discovery that pollen from different sources contains varying amounts of the ethylene precursor ACC, led to the proposal that pollen-borne ACC could account for the ethylene produced by the style immediately after pollination (Whitehead et al., 1983). Petunia pollen may contain as much as $1500 \mathrm{nmol} \cdot \mathrm{g}^{-1}$ ACC (Hoekstra and Weges, 1986; Singh et al., 1992). Singh et al. (1992) reported that the endogenous ACC content of pollen correlated with the amount of ethylene produced by petunia styles immediately after pollination. They concluded that this early ethylene was due to the conversion of pollen-borne ACC to ethylene. In support of this conclusion, it is known that an unpollinated petunia stigma has high levels of ACC oxidase activity and the ability to convert applied ACC to ethylene at anthesis (Jones and Woodson, 1997; Pech et al., 1987; Tang et al., 1994; Tang and Woodson, 1996).

The male gametophyte (pollen grain) has been well characterized biochemically and cytologically. The differentiation of pollen involves a well orchestrated sequence of events including meiosis to form a tetrad of haploid microspores, which are subsequently released to undergo mitosis generating a single binucleate or trinucleate pollen grain. Recently, the development of the male gametophyte has been characterized at the molecular level and a number of pollen-specific genes have been identified (Twell, 1994). These genes are often differentiated into two classes based on their pattern of expression. The early genes are expressed postmeiotically and their transcripts subsequently decline during the maturation of the pollen grain (Albani et al., 1990; Custers et al., 1997; Oldenhof et al., 1996). The late genes are typically expressed following mitosis and are associated with the maturation of the pollen grain (Allen and Lonsdale, 1993; Brown and Crouch, 1990; Twell et al., 1989; Twell et al., 1991; Wing et al., 1989). A number of the late genes have been characterized and 
Table 1. Primers used for PCR reactions and primer extension.

\begin{tabular}{ll}
\hline \hline Primer & Primer extension \\
\hline Primer A & 5'-GCCGAATTCATGGG(G/A/T/C)CT(G/A/T/G)GC(G/A/T/C)GA(G/A)AA(T/C)CA-3' $^{\prime}$ \\
Primer B & 5'-GCCAAGCTTCC(G/A)TG(GA)TA(G/A)TC(T/C)TG(G/A)AA-3' \\
Primer C & 5'-GGCGGATCCAAAACCCTGACGCA-3' \\
Primer D & 5'-CCGGAATTCA(G/A)CA(G/A/T/C)AC(G/A/T/C)C(G/T)(G/A)AACCA(G/A/T/C)CC-3' \\
Primer E & 5'-AGGAGGTAGGTAGGCACTATGA-3' \\
\hline
\end{tabular}

shown to encode proteins that are thought to play a role in pollen germination and tube growth. These include pectate lyase (Wing et al., 1989) and polygalacturonase (Allen and Lonsdale, 1993; Brown and Crouch, 1990). In this paper we report that petunia pollen accumulates the ethylene precursor ACC late during development and this accumulation is associated with the expression of a pollen-specific ACC synthase gene $(P H-A C S 2)$. Further, we show that the $P H-A C S 2$ promoter is capable of directing the expression of a chimeric $\beta$-glucuronidase (GUS) gene in transgenic petunia pollen. Our data clearly show that the $P H$-ACS2 gene is a member of the late genes involved in pollen development and that its expression is associated with the production of ACC in the pollen grain.

\section{Materials and Methods}

Plant material. Plants of 'Mitchell' Petunia hybrida were maintained under standard greenhouse conditions. Supplemental lighting was used to extend daylength to $16 \mathrm{~h}$. Flowers were staged by length, measuring from the base of the calyx to the tip of the corolla. Bud lengths for the various stages were as follows: stage $1,<2 \mathrm{~cm}$; stage 2,2 to $4 \mathrm{~cm}$; stage 3 , flowers 4 to $6 \mathrm{~cm}$ (corolla fully elongated); stage 4, flowers were open but the anthers were not dehiscent; stage 5, flowers were open with dehiscent anthers.

AcC Determination. Pollen was collected from dehiscent anthers in a $1.5-\mathrm{mL}$ microcentrifuge tube using a vortex. ACC was extracted from pollen in $80 \%$ ethanol, centrifuged and the supernatant evaporated to dryness. The residue was resuspended in water and the ACC content was determined following conversion to ethylene as previously described (Lizada and Yang 1979).

RT-PCR AND CDNA CLONING. Ten $\mu \mathrm{g}$ of total RNA isolated from anthers was reverse transcribed at $37^{\circ} \mathrm{C}$ using M-MLV reverse transcriptase and oligo $\mathrm{dT}$ as a primer. The products of this reaction were used to amplify ACC synthase cDNA using two degenerate primers: primer $\mathrm{A}$ and $\mathrm{B}$ (Table 1 ). The PCR reaction was performed with 35 cycles at $95^{\circ} \mathrm{C}$ denaturation, $50{ }^{\circ} \mathrm{C}$ annealing, and $72^{\circ} \mathrm{C}$ amplification at $1 \mathrm{~min}$ per cycle. The first cycle was preceded by one cycle at $94{ }^{\circ} \mathrm{C}$ for $3 \mathrm{~min}$ and the last cycle followed by one 7 -min cycle at $72^{\circ} \mathrm{C}$. A $134 \mathrm{bp}$ product was produced, subcloned into pGEM7Zf(+) (Promega, Madison, Wis.), and its nucleotide sequence determined (Sanger et al. 1977). Sequence information from this product was used to synthesize a specific primer, primer $\mathrm{C}$ (Table 1). This primer, in conjunction with the degenerate primer D (Table 1), was used with petunia anther cDNA in a touchdown PCR reaction (Don et al., 1991). Denaturation and amplification conditions were identical to the first reaction. Annealing temperatures were reduced from 63 to $51^{\circ} \mathrm{C}$ at $2{ }^{\circ} \mathrm{C}$ intervals, each for two cycles, followed by 30 cycles at an annealing temperature of $50^{\circ} \mathrm{C}$. The 1.1-kb product was cloned into pGEM7Zf(+), sequenced, and designated pPHACS2. Radiolabeled pPHACS2 was used to screen a Petunia hybrida cv Mitchell genomic library as previously described (Tang et al. 1993). Hybridizing plaques were purified and insert DNA isolated for restriction enzyme analysis and subcloning into pGEM7Zf(+).
RNA EXTRACTION AND GEL BLOT ANALYSIS. Total RNA from petunia tissue was extracted as described by Lawton et al., (1990) and quantified spectrophotometrically. RNA was extracted from anthers from flowers staged as shown in Fig. 1. RNA was also extracted from mature pollen, styles, ovaries, petals, leaves, wounded leaf and auxin treated leaves. Leaves were wounded with a wire dog grooming brush by a single impact and tissue was collected for RNA extraction $2 \mathrm{~h}$ after wounding. Auxin treated leaves were incubated for $24 \mathrm{~h}$ in $100 \mu \mathrm{M}$ IAA. Twenty micrograms of total RNA was separated by electrophoresis through a $1 \%(\mathrm{w} /$ v) agarose gel containing $2.2 \mathrm{~m}$ formaldehyde. Separated RNAs were transferred to Nytran membranes (Schleicher and Schuell) and cross-linked with a Stratalinker controlled UV light source (Stratagene). Membranes were prehybridized and hybridized as previously described (Jones et al., 1995). Membranes were hybridized for $20 \mathrm{~h}$ at $42^{\circ} \mathrm{C}$ with $5 \times 10^{5} \mathrm{cpm} / \mathrm{mL} 32 \mathrm{P}$-labeled $P H-A C S 2$. The $P H$-ACS 2 probe consisted of $1270 \mathrm{bp}$ at the 3 -prime end of the fourth exon. Membranes were washed in $2 \times \mathrm{SSC}(1 \times \mathrm{SSC}$ is 0.15 $\mathrm{M} \mathrm{NaCl}, 15 \mathrm{~mm}$ sodium citrate, $\mathrm{pH} 7.0$ ) and $0.1 \%$ SDS for $15 \mathrm{~min}$ at room temperature followed by $15 \mathrm{~min}$ at $55^{\circ} \mathrm{C}$. Blots were exposed to Kodak XAR-5 film at $-80{ }^{\circ} \mathrm{C}$ for $6 \mathrm{~d}$ using a single intensifying screen. To evaluate RNA loading, blots were reprobed with a flax ribosomal RNA sequence (Goldsbrough and Cullis, 1981).
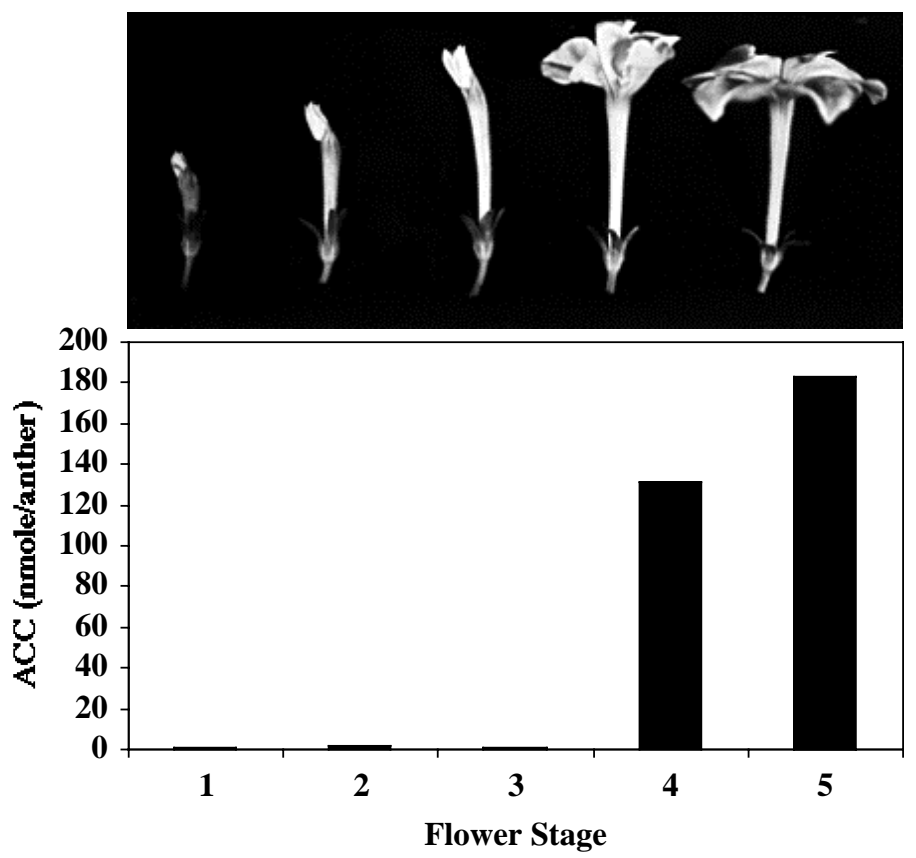

Fig. 1. Accumulation of ACC in petunia anthers during flower development. Stages of flower development are depicted in the picture. Flowers were staged measuring from the base of the calyx to the tip of the corollas: Stage 1, 3 to $4 \mathrm{~cm}$; Stage 2, 4 to $5 \mathrm{~cm}$; Stage 3, 5 to $6 \mathrm{~cm}$; Stage 4, flower open, anther not dehiscing; Stage 5 , flowers open, anthers dehiscent. Anthers were extracted in $80 \%$ ethanol and ACC content determined following conversion to ethylene as previously described in Lizada and Yang (1979). 
Primer extension. The transcription start site was identified using primer extension, performed according to the methods of Ausubel (1995). One hundred fifty nanograms of primer E (Table 1) was end labeled with ${ }^{32} \mathrm{P}$-ATP. Fifty micrograms of total RNA from stage 4 and stage 5 anthers was hybridized with the labeled probe for $3 \mathrm{~h}$ at $65^{\circ} \mathrm{C}$. Reverse transcriptase mediated extension was carried out for $1 \mathrm{~h}$ at $42^{\circ} \mathrm{C}$ and the products were analyzed on an $8 \%$ polyacrylamide gel.

Promoter deletion analysis. Five different deletions were generated from the 5-prime end of $P H$-ACS2. The deletions were constructed using a series of PCR primers that when amplified gave promoter fragments of the following lengths: $-846,-616$, $331,-3$, and 155 . Primers were designed to contain a SalI site at the 5-prime end, and a BamHI site at the 3-prime end. The 3-prime end of each deletion was located at +329 of the $P H$-ACS 2 sequence. These PCR fragments were purified from an agarose gel and then digested with SalI and BamHI and ligated directly into pBI101.2 as translational fusions with the GUS gene. Since the resulting GUS protein was a fusion product, care was taken to ensure that the GUS coding region was in frame with the 5-prime end of the $\mathrm{PH}$ $A C S 2$ protein, also found in the fusion product.

Plant transformation. Transgenic petunias were produced using both the full-length $P H-A C S 2$ constructs and the deletion series. Petunia leaf disks were transformed as described by Jorgensen et al. (1996) except that acetylsyringone was not used and selection on kanamycin was at $50 \mu \mathrm{g} \cdot \mathrm{mL}^{-1}$. Shoots that rooted in the presence of kanamycin were transferred to soil, established to greenhouse conditions and grown to flowering. Pollen was collected from transgenic plants and the pollen stained for $\beta$-glucuronidase (GUS) activity using 5-bromo-4-chloro-3-indolyl- $\beta$-Dglucuronide as a substrate (Stomp 1992). Methanol (20\% v/v) was included in the GUS staining solution to reduce endogenous background (Kosugi et al. 1990).

ACC SYNTHASE INDUCTION EXPERIMENTS. A number of treatments known to induce ACC synthase in other systems were conducted in order to demonstrate the pollen specific nature of $\mathrm{PH}$ $A C S 2$ expression. Cuttings were rooted from plants expressing $P H-A C S 2-G U S$ in pollen. The roots of these plants were submerged in water for $48 \mathrm{~h}$, harvested and stained for GUS activity. Stigmas from transgenic plants expressing $P H-A C S 2-G U S$ were pollinated either with wild type or transgenic pollen. Styles were removed $24 \mathrm{~h}$ after pollination and stained for GUS activity. Mature leaves from transgenic petunias expressing $\mathrm{PH}$-ACS2$G U S$ were excised from plants and treated overnight with $100 \mu \mathrm{M}$ 2,4-D then stained for GUS. Mature leaves were also wounded with a wire dog grooming brush and stained for GUS activity. Transgenic (T1) petunia seeds from lines staining positive for GUS activity in pollen were germinated and grown for 7 to $10 \mathrm{~d}$ in the dark on Murashige and Skoog (1962) media without hormones. Etiolated seedlings (at least 10) were transferred to MS media containing either 1,10 , or $100 \mu \mathrm{M}$ IAA. Seedlings were incubated in the dark on this media for $24 \mathrm{~h}$ and then stained for GUS activity. Etiolated seedlings were also maintained in the dark on basal MS (Murashige and Skoog 1962) media but transferred to an airtight $22.4 \mathrm{~L}$ chamber through which nitrogen was passed at $50 \mathrm{~mL} \cdot \mathrm{min}^{-}$ ${ }^{1}$. Seedlings were maintained in this environment for 24 or $48 \mathrm{~h}$ and then stained for GUS activity. Petunia seedlings expressing GUS constitutively were used as positive controls.

\section{Results}

ACC ACCUMUlation In DEVELOPING ANTHERS. Petunia pollen has been shown to contain as much as $1,000 \mathrm{nmol} \cdot \mathrm{g}-1$ of ACC
(Hoekstra and Weges, 1986; Singh et al., 1992). In order to determine if the accumulation of this ACC is developmentally regulated, anthers were assayed for ACC content at various stages of flower development. Little ACC was detected in anthers from immature flower buds at stages 1 through 3 (Fig. 1). The transition from stage 3 to 4 during the early stages of flower opening was associated with a 100-fold increase in ACC content in anthers. The level of ACC continued to increase, until anther dehiscence at stage 5. This data indicates that the accumulation of ACC in pollen is a late event in development, occurring during the final stages of pollen maturation.

ISOLATION OF AN ACC SYNTHASE CDNA BY RT-PCR. To identify an ACC synthase gene expressed in developing anthers, we used degenerate oligonucleotide primers (primers A and B; Table 1) based on conserved sequences of ACC synthases isolated from a number of plant species. Total RNA isolated from stage 5 anthers was used in a reverse transcription reaction. The resulting cDNA was used as a template for the PCR reaction in the presence of degenerate primers. A 134-bp RT-PCR product was isolated following electrophoresis, subcloned into pGEM7Zf(+) and sequenced. Based on this sequence information, a specific 5-prime primer (primer C; Table 1) was generated, which was used in combination with a degenerate 3-prime primer (primer D) to amplify an ACC synthase cDNA from anther RNA. This yielded

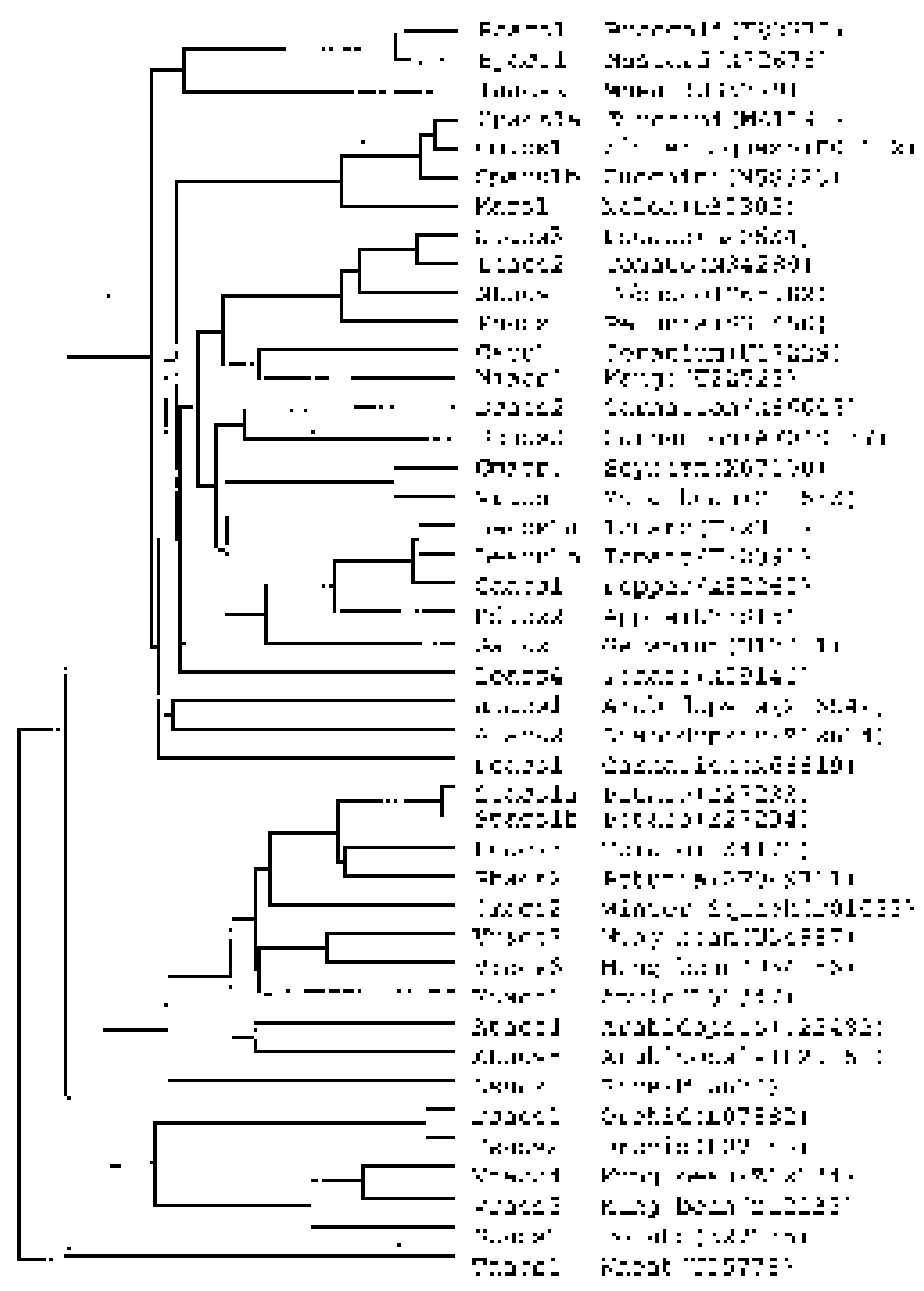

Fig. 2. Phylogenetic analysis of ACC synthases from several plant species. Sequence alignment was obtained using the PILEUP program, part of the Wisconsin Sequence Analyze Package (Devereux et al., 1984). The Genbank accession numbers for each sequence are in parentheses. 
Fig. 3. Expression of $P H-A C S 2$ mRNA during anther development and other Petunia tissue. (A) Total RNA was extracted from anthers at stages of development illustrated in Fig. 1 and from pollen from stage 5 flowers. (B) RNA was extracted from the tissue indicated. Twenty micrograms of total RNA was separated by electrophoresis through agarose under denaturing conditions, transferred to nylon membrane and probed using 1270-bp 3-prime from the fourth exon of $\mathrm{PH}$ ACS2. A flax ribosomal RNA probe was used to check RNA loadings (Goldsbrough and Cullis 1981).

a 1.1-kbcDNA, which was subcloned into pGEM7Zf (+) and designated pPHACS2. The nucleotide

sequence of pPHACS2 was determined (data not shown) and shared $70 \%$ nucleotide identity with the petunia ACC synthase PHACSI in the coding region (Michael et al., unpublished; EMBL Accession No. Z18953). Based on sequence homology with other ACC synthases, pPHACS2 was not full length and was missing both 5and 3-prime sequences.

IDENTIFICATION AND CHARACTERIZATION OF THE PH-ACS2 GENE. To identify the $P H$-ACS2 gene, a library of genomic fragments from petunia was screened with the pPHACS2 partial cDNA. This screen identified two independent genomic clones representing an overlapping region of the genome of $\approx 15 \mathrm{kbp}$. These genomic clones were digested with restriction enzymes and the resulting fragments cloned into pGEM7Zf $(+)$ for nucleotide sequencing. A region of $3.7 \mathrm{kbp}$ that hybridized to the pPHACS2 cDNA clone was completely sequenced and shown to encode the PH-ACS2 gene in four exons, interrupted by three introns (GenBank accession number AF049711). The predicted PH-ACS2 peptide contained 470 amino acids with a molecular weight of 52,993 and a pI of 6.71. The $P H$-ACS2 protein shares over $85 \%$ identify with ACC synthases from tomato ( $L E$-ACS3; Olson et al., 1995) and potato (ST-ACS1a and ST-ACS1b; Destéfano-Beltrán et al., 1995). In contrast, the full length $P H$-ACS2 peptide shares only $52 \%$ identity with the only other reported ACC synthase from petunia $(\mathrm{PH}$ ACS1; EMBL Accession No. Z18953). The $P H$-ACS2 polypeptide was compared to 42 other known ACC synthases found in the protein databases (Fig. 2). This analysis is presented in Fig. 2 and shows that $P H-A C S 2$ is more similar to ACC synthase polypeptides from other species than to the other known ACC synthase from petunia. The $P H-A C S 2$ polypeptide contained the conserved dodecapeptide SLSKPLGLPGFR in exon 4, that is part of the active site of ACC synthases (Fluhr and Mattoo, 1996; Yip et al., 1990). PH-ACS2 also contained the 11 invariant amino acids conserved in ACC synthases and amino transferases (Fluhr and Mattoo, 1996).

The structure of the PH-ACS2 gene was compared to other known ACC synthase genes (Table 2). The four exons encoding the $P H-A C S 2$ transcript are interrupted by three introns with consensus 5-prime GT and 3-prime AG dinucleotides located at their boundaries. The intron positions are identical to those of the $L E-A C S 3$ gene; however, the introns share little sequence similarity. Two of the three introns are conserved with the potato ACC synthase genes, ST-ACSI $a$ and ST-ACSIb. The counterpart first intron is missing in the potato genes. The nucleotide sequence of the $P H$-ACS2 exons are highly conserved with respect to the $L E$ $A C S 3$ and ST-ACSIa genes, sharing over $80 \%$ homology. A specific oligonucleotide primer (primer E; Table 1) representing the 5-prime untranslated region of the $P H$-ACS2 gene was used to determine the transcriptional start site by primer-extension analysis. This primer, along with total RNA isolated from mature anthers as a template, was used for primer extension and yielded a single product (data not shown; GenBank accession number AF049711). This revealed that the cloned PH-ACS2 gene contained over $1000 \mathrm{bp}$ of upstream sequence. A sequence was identified 41 nucleotides upstream of the transcriptional start site and likely represents the TATA box. The 5-prime regions of $P H$ ACS2, LE-ACS3 and ST-ACS1 $a$ share little homology. In contrast to the 5-prime region, the 3-prime untranslated region of $\mathrm{PH}-\mathrm{ACS} 2$ and LE-ACS3 share $>70 \%$ homology over a span of 250 nucleotides. Taken together, these data indicate that the $P H-A C S 2$ gene is a close homologue to the tomato LE-ACS3 gene.

EXPRESSION OF THE PH-ACS2 GENE. To determine the pattern of expression of the $P H-A C S 2$ gene during pollen development, total RNA isolated from anthers at the five stages of floral development was analyzed by RNA gel blots using pPHACS2 as a probe (Fig. $3 \mathrm{~A})$. The stages in the northern blot correspond to the flowers shown in Fig. 1. pPHACS2 transcripts were first detected in anthers from Stage 4 flowers, concomitant with the first evidence of ACC accumulation shown in Fig. 1. Continued development of flowers was associated with high levels of $P H-A C S 2$ mRNA. Pollen isolated from dehiscent anthers was analyzed for the presence of $P H-A C S 2 \mathrm{mRNA}$ by northern blot analysis. This revealed the presence of high levels of $P H-A C S 2$ mRNA and indicates that the $P H-A C S 2$ gene is likely expressed in the developing pollen grain. Expression of pPHACS2 was unique to pollen and anthers as no transcripts of $P H-A C S 2$ were detected in RNA from leaves, ovaries or petals of petunia (Fig. 3B). The $P H-A C S 2$ gene is most similar to ACC synthases from tomato ( $L E-A C S 3)$ and potato ( $S T$ $A C S 1 a$ and $S T-A C S 1 b$ ), which have previously been shown to be expressed in response to the hormone auxin (Destéfano-Beltrán et al., 1995; Yip et al., 1992). Also, the LE-ACS3 gene has been shown to be expressed in response to wounding (Yip et al., 1992). We did not detect increased levels of the PH-ACS2 transcript following wounding of leaves or treatment with auxin (Fig. 3B). Taken together, this data reveal that the $P H-A C S 2$ gene is expressed specifically in pollen late during development, just before anther dehiscence and does not appear to be regulated by wounding or the plant hormone auxin.

THE PH-ACS2 PROMOTER DIRECTS POLLEN-SPECIFIC EXPRESSION OF A CHIMERIC GUS GENE. Using a translational PH-ACS2-GUS fusion, we generated transgenic petunias expressing GUS under control of the $1057 \mathrm{bp} \mathrm{PH-ACS2}$ promoter. Pollen was isolated from a number of independent transformed plants at anthesis and assessed for GUS activity by histological staining. This revealed that the chimeric PH-ACS2-GUS gene was expressed in mature pollen (Fig. 4). No activity of GUS could be detected in pollen isolated from immature pollen before stage 3 (data not shown). In order to determine if there are cis-elements present in the 5-primeflanking regions of the $\mathrm{PH}-\mathrm{ACS} 2$ gene that are responsible for the expression in pollen, a series of 5-prime-deletions were generated using PCR and fused to the GUS reporter gene. These chimeric genes were introduced into petunia by Agrobacterium-mediated transformation and the transgenic plants analyzed for GUS expression (Fig. 4). Promoters containing 846, 616 and 331 bp of 5prime-flanking DNA all led to the expression of GUS in pollen of 


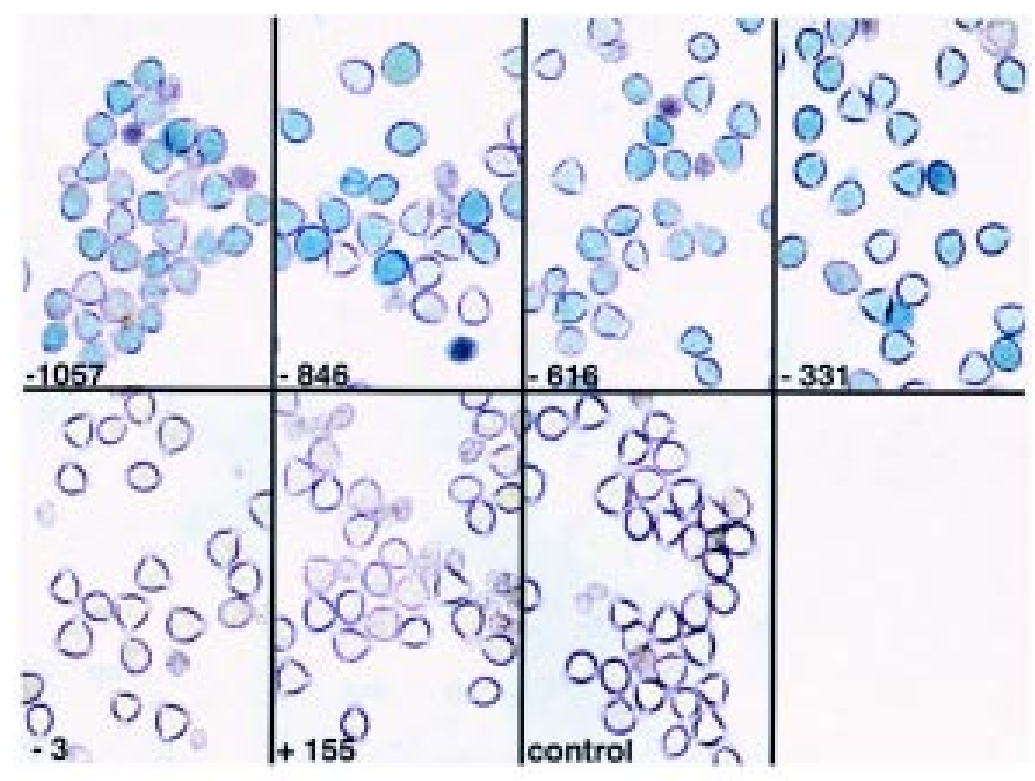

and Weges, 1986; Singh et al., 1992; Whitehead et al., 1983). In petunia flowers, pollination leads to a very rapid burst of ethylene production by the stigma, which may be partially mediated by the transfer of ACC from pollen to the stigmatic surface during pollen hydration (Singh et al., 1992). Consistent with this, ACC oxidase activity (Pech et al., 1987) and mRNA levels (Tang et al., 1994; Tang and Woodson, 1996) increase to high levels at anthesis, leading to increased capacity to convert ACC to ethylene. As a first step in studying the role of pollen-born ACC in pollinationinduced ethylene production, we have investigated the accumulation of ACC in petunia pollen. Here we report that ACC accumulates in pollen just before anthesis at a stage when pollen grains are undergoing the final stages of maturation. Pollak et al., (1993) studied the development of petunia pollen and reported that the death of the sporophytic tapetal tissue and release of the haploid microspores from the tetrad occur well before flowers are fully elongated. Further, they show that the mitotic events associated with the formation of the

Fig. 4. Expression of the $P H-A C S 2-G U S$ fusion gene and promoter deletions of the PH-ACS2-GUS in transgenic petunia. Pollen was isolated and stained for GUS from the full length construct and the following five deletions (numbered in relation to the transcription start site): $-846,-616,-331,-3,155$. Control (untransformed pollen) was also stained for GUS

transgenic petunias. A deletion of all 5-prime-flanking DNA including the putative TATA box resulted in no detectable GUS activity of a number of independent transgenic plants. Further, a deletion ending $155 \mathrm{bp}$ downstream of the transcriptional start site was similarly inactive. Taken together, this data indicates that sequences between -331 and the transcriptional start site are necessary for pollen-specific expression of $P H-A C S 2$.

Previously, it was reported that the $L E-A C S 3$ gene was responsive to auxin (Yip et al., 1992) and flooding (Olson et al., 1995). Given the high level of homology between $P H$-ACS2 and $L E$ $A C S 3$, we investigated whether the $P H-A C S 2$ promoter was capable of directing the expression of GUS in response to these stimuli. Transgenic petunias carrying the full length promoter fused to GUS were analyzed for expression under conditions of flooding and auxin treatment. No GUS activity was detected when roots were flooded for $48 \mathrm{~h}$ or when mature, detached leaves or seedlings were treated with auxin. Similarly, wounding of mature leaves from transgenic plants did not result in GUS expression (data not shown). No GUS activity could be detected in transgenic plants carrying the $\mathrm{PH}$-ACS2-GUS gene except in pollen. Stigmas of transgenic plants did not stain for GUS activity (Fig. 5). However, when pollinated with transgenic pollen from $\mathrm{PH}$-ACS2$G U S$ plants, GUS activity could be detected on the stigmatic surface. Furthermore, GUS activity was detected on the stigmatic surface of wild-type 'Mitchell' plants pollinated with $\mathrm{PH}$-ACS2GUS pollen (Fig. 5). These data indicate that $P H-A C S 2$ is a pollenspecific gene and sequences in the 5-prime-flanking region of this gene are necessary for expression in pollen.

\section{Discussion}

Petunia pollen has previously been found to contain the ethylene precursor ACC at levels greater than $1,000 \mathrm{nmol} \cdot \mathrm{g}^{-1}$ (Hoekstra binucleate pollen grain occur at a stage before ACC accumulates in pollen. Given the lack of association of the maturing pollen grains with the sporophytic tissue of the anther at the final stages of development when ACC accumulates, our results suggest that ACC is synthesized directly in the haploid pollen grain by either the vegetative or generative cell of the binucleate pollen.

The enzyme ACC synthase catalyzes the conversion of $S$ adenosyl-L-methinonine to ACC. Genes encoding ACC synthase have been identified in a number of plant species (Fluhr and Mattoo, 1996). In an effort to elucidate the molecular basis for ACC accumulation in petunia pollen, we utilized RT-PCR to amplify an ACC synthase cDNA from mature anthers. This cDNA was used to identify the $P H$-ACS 2 gene from a library of petunia genomic fragments. The $P H-A C S 2$ gene encoded an ACC synthase protein based on extensive homology with other ACC synthases from tomato ( $L E-A C S 3)$ and potato (ST-ACSIa and ST$A C S 1 b$ ). In addition, the predicted $P H$ - $A C S 2$ protein contained all 11 of the invariant amino acids found in other functional ACC synthases (Fluhr and Mattoo, 1996) and the sequence of the enzyme's active site was completely conserved (Yip et al., 1990). The tomato counterpart to the $P H-A C S 2$ gene shared a similar structure with 4 exons interrupted by 3 introns in the identical

Table 2. Comparison of the structures of the PH-ACS2 gene with $L E$ $A C S 3$ and ST-ACS1a.

\begin{tabular}{lcc}
\hline \hline & \multicolumn{2}{c}{ Homology $(\%)$} \\
\cline { 2 - 3 } Region & LE-ACS3 & ST-ACS1a \\
\hline 5-Prime distal & 42 & 43 \\
5-Prime proximal & 44 & 39 \\
Exon 1 & 88 & 84 \\
Intron 1 & 49 & nd \\
Exon 2 & 89 & 83 \\
Intron 2 & 49 & 44 \\
Exon 3 & 85 & 86 \\
Intron 3 & 52 & 40 \\
Exon 4 & 79 & 81 \\
3-Prime untranslated & 70 & 38 \\
\hline
\end{tabular}




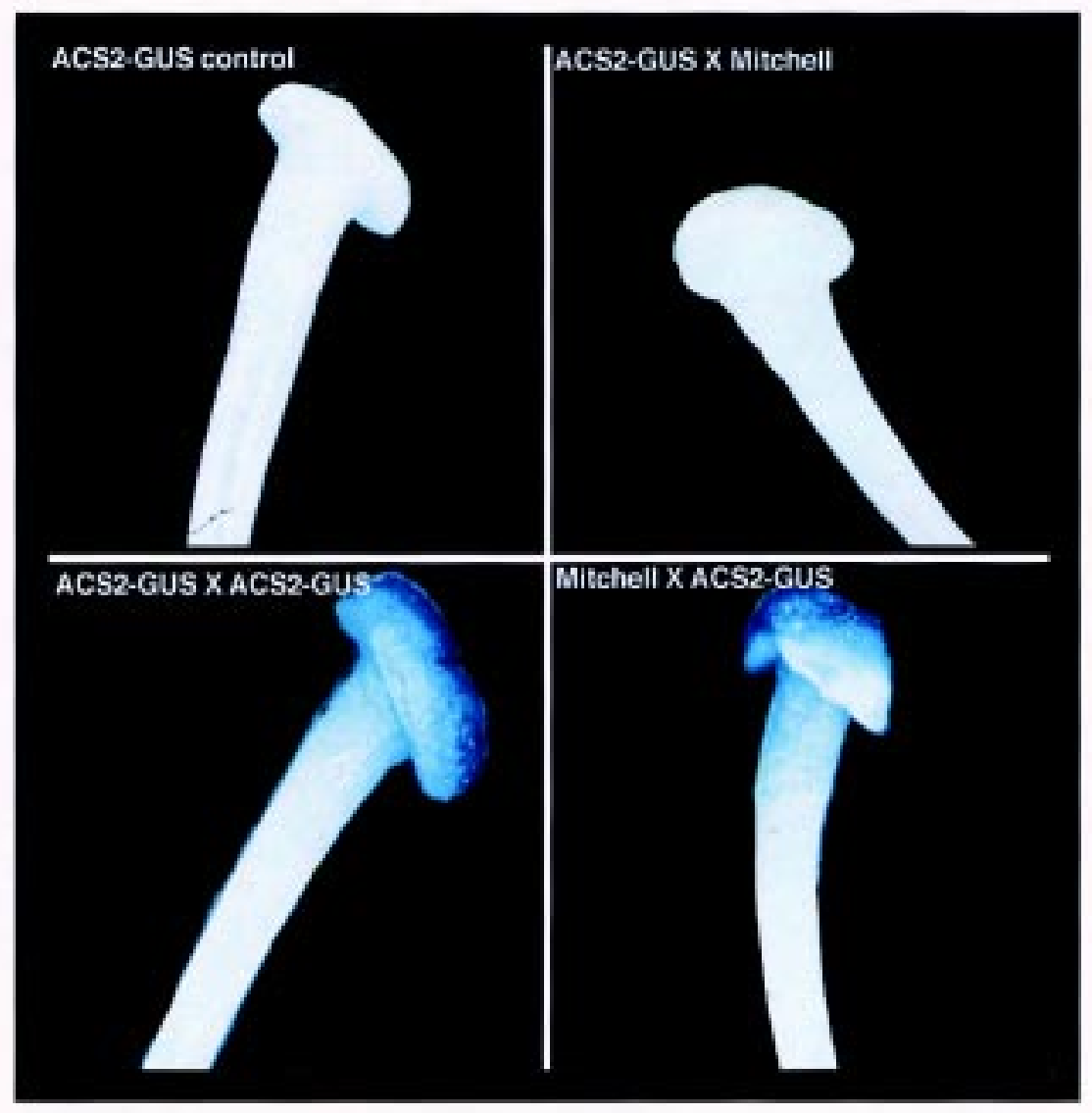

proteins thought to play a role in pollen development and/or pollen germination. These include polygalac-turonase (Brown and Crouch, 1989; Allen and Lonsdale, 1993), pectic lyase (Wing et al., 1989), and chalcone flavanone isomerase (Van Tunen et al., 1989). Our data points to ACC synthase as being another example of a gene expressed in maturing pollen that encodes a protein functioning in the metabolism of the pollen grain.

The promoter of the $P H-A C S 2$ gene was shown to direct the transcription of a chimeric GUS reporter gene specifically in pollen of transgenic petunia plants. We analyzed the promoter for potential cis-acting sequences found in other pollen-specific genes. Previously, the LAT 52, 56 and 59 genes were shown to contain sequences in their 5' flanking DNA that were necessary for expression in pollen (Twell et al., 1991; Twell, 1994). The GTGG/CACC box was shown to represent a function core motif for pollen expression. Deletion analysis of the $P H-A C S 2$ promoter revealed that sequences between -331 and -3 were necessary for pollen-specific expression. A scan of this region for the core pollen motif identified an element between -158 to -153 (CACCAT) that is homologous to the sequences found in the tomato pollen-specific promoters. Targeted mutation of this element from the $L A T$ 52 gene showed that this sequence was necessary for maximal expression in pollen (Twell, 1994). Similar elements have been identified in other

Fig. 5. Expression of the $P H-A C S 2-G U S$ fusion gene in transgenic petunia. Control or transgenic styles were pollinated with control or transgenic pollen. (top left) transgenic control (unpollinated); (bottom right) transgenic pollen on 'Mitchell' style; (bottom left) transgenic pollen on transgenic style; (top right)'Mitchell' pollen on transgenic style.

position (Olson et al., 1995). While introns between the two genes shared little homology, the 3-prime untranslated region was well conserved, with $>70 \%$ homology in a span of $200 \mathrm{bp}$. In contrast, the potato genes, while sharing $>85 \%$ amino acid identity with the PH-ACS2 gene, did not share the same structural features. These genes did not contain the first counterpart intron and shared little homology in the 3-prime region (Destéfano-Beltrán et al., 1995). Interestingly, the potato genes are closely linked and transcribed in opposite directions. It is not clear that tomato or petunia share this structure with a closely linked homologue to the $L E-A C S 3$ or $P H$ $A C S 2$ genes, respectively. However, this can not be ruled out at the present time given the limited data on the flanking sequences of these genes.

Expression studies revealed the $P H-A C S 2$ gene was expressed concomitant with the accumulation of ACC in developing anthers. Further, the $P H-A C S 2$ transcript was detected in mature pollen and not in other tissues. In spite of the significant homology found between the $\mathrm{PH}-\mathrm{ACS} 2$ gene and other auxin-responsive genes from tomato (Yip et al., 1992) and potato (Destéfano-Beltrán et al., $1995)$, the $P H$-ACS2 transcript was not detected in auxin- and/or wounded leaves. Taken together, this data suggests that the $P H$ ACS2 gene encodes a pollen-specific ACC synthase that leads to the production of ACC in the maturing pollen grain. From our data, it is clear that the $\mathrm{PH}-\mathrm{ACS} 2$ gene is representative of the late class of genes expressed during the final stages of pollen development (Twell, 1994). A number of genes have been identified that encode pollen specific genes (see Twell, 1994 for review).

In summary, the accumulation of ACC in petunia pollen is a late developmental event and is likely the result of the expression of a pollen-specific ACC synthase gene. At present, the role of ACC in pollen is unclear, but previous research has suggested that it plays a role in pollination-induced ethylene (Hill et al., 1987; Singh et al., 1992). The identification of a pollen-specific ACC synthase will open the way for us to address this role directly using genetic engineering approaches to inhibit the expression of the ACC synthase gene and therefore limit the production of ethylene.

\section{Literature Cited}

Albani, D., L.S Robert, P.A. Donaldson, I Altosaar, P.G. Arnison, and S.F. Fabijanski. 1990. Characterization of a pollen-specific gene family from Brassica napus which is activated during early microspore development. Plant Mol. Biol. 15:605-622.

Allen, R.L. and D.M. Lonsdale. 1993. Molecular characterization of one of the maize polygalacturonase gene family members which are expressed during late pollen development. Plant J. 3:261-271.

Ausubel, F.M. 1995. Short protocols in molecular biology: a compendium of methods from Current Protocols in Molecular Biology. Wiley, New York, NY

Brown, S.M. and M.L. Crouch. 1990. Characterization of a gene family abundantly expressed in Oenothera organensis pollen that shows sequence similarity to polygalacturonase. Plant Cell 2:263-274.

Custers, J.B.M., M.T. Oldenhof, J.A.M. Schrauwen, J.H.G. Cordewener, G.J. Wullems, and M.M. van Lookeren Campagne. 1997. Analysis of microspore-specific promoters in transgenic tobacco. Plant Mol. Biol. 35:689-699.

Destéfano-Beltrán, L.J.C., W. Van Caeneghem, J. Gielen, L. Richard, M. Van Montagu, D. Van der Straeden. 1995. Characterization of three members of the ACC synthase gene family in Solanum tuberosum L. 
Mol. Gen. Genet. 246:496-508.

Devereux, P., P. Haeberli, and O. Smithies. 1984. A comprehensive set of sequence analysis programs for the VAX. Nucl. Acids Res. 12:387-395.

Don, R.H., P.T. Cox, B.J. Wainwright, K. Baker, and J.S. Mattick. 1991. 'Touchdown' PCR to circumvent spurious priming during gene amplification. Nucl. Acids Res. 19: 4008.

Felix, G., D.G. Grosskopf, M. Regenass, C.W. Basse, and T. Boller. 1991. Elicitor-induced ethylene biosynthesis in tomato cells. Characterization and use as a bioassay for elicitor action. Plant Physiol. 97:19-25.

Fluhr, R. and A.K. Mattoo. 1996. Ethylene-Biosynthesis and perception. Crit. Rev. Plant Sci. 15:479-523.

Goldsbrough, P.B. and C.A. Cullis. 1981. Characterization of the genes for ribosomal RNA in flax. Nucl. Acids Res. 9:1301-1309.

Hill, S.E., A.D. Stead, and R. Nichols. 1987. Pollination-induced ethylene and production of 1-aminocyclopropane-1-carboxylic acid by pollen of Nicotiana tabacum cv White Burley. J. Plant Growth Regul. 6: 1-13.

Hoekstra, F.A. and R. Weges. 1986. Lack of control by early pistillate ethylene of the accelerated wilting of Petunia hybrida flowers. Plant Physiol. 80: 403-408.

Jones, M.L., P.B. Larsen, and W.R. Woodson. 1995. Ethylene-regulated expression of a carnation cysteine proteinase during flower petal senescence. Plant Mol. Biol. 28:505-512.

Jones, M.L. and W.R. Woodson. 1997. Pollination-induced ethylene in carnation-Role of stylar ethylene in corolla senesence. Plant Physiol. 115:205-212.

Jorgensen, R.A., P.D. Cluster, J. English, Q. Que, and C.A. Napoli. 1996. Chalcone synthase cosuppresion phenotypes in petunia flowers: comparison of sense vs. antisense constructs and single-copy vs. complex TDNA sequences. Plant Mol. Biol. 31:957-973.

Kende, H. 1993. Ethylene biosynthesis. Annu. Rev. Plant Physiol. Plant Mol. Biol. 44: 283-307.

Kosugi, S., Y. Ohasi, K. Nakajima, and Y. Arai. 1990. An improved assay for $\beta$-glucuronidase in transformed cells: Methanol almost completely suppresses a putative endogenous $\beta$-glucuronidase activity. Plant Sci. 70:133-140.

Larsen, P.B., E.N. Ashworth, M.L. Jones, and W.R. Woodson. 1995. Pollination-induced ethylene in carnation role of pollen tube growth and sexual compatibility. Plant Physiol. 108:1405-1412.

Lasserre, E., T. Bouguin, J. A. Hernandez, J. Bull, J.-C. Pech and C. Balague. 1996. Structure and expression of three genes encoding ACC oxidase homologs from melon (Cucumis melo L.). Mol. Gen. Genet. 251:81-90.

Lawton, K.A., K.G. Raghothama, P.G. Goldsbrough, and W.R. Woodson. 1990. Regulation of senescence-related genes from carnation flower petals by ethylene. Plant Physiol. 93: 1370-1375.

Liang, X.W., S. Abel, J.A. Keller, N.F. Shen, and A. Theologis. 1992. The 1-aminocyclopropane-1-carboxylate synthase gene family of Arabidopsis thaliana. Proc. Natl. Acad. Sci. USA 89:11046-11050.

Liang, X.W., N.F. Shen, and A. Theologis. 1996. Li+ regulated 1aminocyclopropane-1-carboxylate synthase gene expression in Arabidopsis thaliana. Plant J. 10:1027-1036.

Lizada, M-C.C. and S.F. Yang. 1979. A simple and sensitive assay for 1aminocyclopropane-1-carboxylic acid. Anal. Biochem. 100: 140-145. Murashige, T. and F. Skoog. 1962. A revised medium for rapid growth and bioassays with tobacco tissue cultures. Physiol. Plant. 15:473-497.

Nichols, R., G. Bufler, Y. Mor, D.W. Fujino, and M.S. Reid. 1983. Changes in ethylene production and 1-aminocyclopropane-1-carboxylate content of pollinated carnation flowers. J. Plant Growth Regul. 2:18.

Oldenhof, M.T., P.F.M. de Groot, J.H. Visser, J.A.M. Schrauwen, and G.J. Wullems. 1996. Isolation and characterization of a microsporespecific gene from tobacco. Plant Mol. Biol. 31:213-225.

Olson, D.C., J.H. Oetiker, and S.F. Yang. 1995. Analysis of $L E-A C S 3$, a 1-aminocyclopropane-1-carboxylic acid synthase gene expressed during flooding in the roots of tomato plants. J. Biol. Chem. 270: 1405614061.
Pech, J-C., A. Latche, C. Larrigaudiere, and M.S. Reid. 1987. Control of early ethylene synthesis in pollinated petunia flowers. Plant Physiol. Biochem. 25: 431-437.

Pollak, P.E., T. Vogt, Y. Mo, and L.P. Taylor. 1993. Chalcone synthase and flavonol accumulation in stigmas and anthers of Petunia hybrida. Plant Physiol. 102:925-932.

Rottmann, W.H., G.F. Peter, P.W. Oeller, J.A. Keller, N.F. Shen, B.P. Nagy, L.P. Taylor, A.D. Campell and A. Theologis. 1991. 1aminocyclopropane-1-carboxylate synthase in tomato is encoded by a multigene family whose transcription is induced during fruit and floral senescence. J. Mol. Biol. 222:937-961.

Sanger, F., S.C. Nicklen, and A.R. Coulsen. 1977. DNA sequencing with chain-terminating inhibitors. Proc. Natl. Acad. Sci. USA 74: $5463-$ 5467.

Singh, A., K.B. Evensen, and T-H. Kao. 1992. Ethylene synthesis and floral senescence following compatible and incompatible pollinations in Petunia inflata.. Plant Physiol. 99: 38-45.

Stead, A.D. 1992. Pollination-induced flower senescence: a review. Plant Growth Regul. 11: 13-20.

Stomp, A-M. 1992. Histochemical localization of $\beta$-glucuronidase. In: Gallagher SR (ed) GUS Protocols, pp 103-113. Academic Press, Inc. San Diego, Calif.

Tang, X., and W.R. Woodson. 1996. Temporal and spatial expression of 1aminocyclopropane-1-carboxylate oxidase mRNA following pollination of immature and mature petunia flowers. Plant Physiol. 112:503-511.

Tang, X., H. Wang, A.S. Brandt, and W.R. Woodson. 1993. Organization and structure of the 1-aminocyclopropane-1-carboxylate oxidase gene family from Petunia hybrida.. Plant Mol. Biol. 23: 1151-1164.

Tang, X., A.M.T.R. Gomes, A. Bhatia, and W.R. Woodson. 1994. Pistilspecific and ethylene-regulated expression of 1-aminocyclopropane-1carboxylate oxidase genes in petunia flowers. Plant Cell 6: 1227-1239.

Twell, D. 1994. The diversity and regulation of gene expression in the pathway of male gametophyte development. In: Scott RJ, Stead AD (eds) Society for Experimental Biology Seminar Series 55: Molecular and Cellular Aspects of Plant Reproduction, pp 83-135. Cambridge University Press, Cambridge UK.

Twell, D., R. Wing, J. Yamaguchi, and S. McCormick. 1989. Isolation and expression of an anther-specific gene from tomato. Mol. Gen. Genet. 217:240-245.

Twell, D., J. Yamaguchi, R.A. Wing, J. Ushiba, and S. McCormick. 1991. Promoter analysis of genes that are coordinately expressed during pollen development reveals pollen-specific enhancer sequences and shared regulatory elements. Genes Devel. 5:496-507.

Van Tunen, A.J., S.A. Hartman, L.A. Mur, and J.N.M. Mol. 1989. Regulation of chalcone flavanone isomerase (CHI) gene expression in Petunia hybrida: the use of alternative promoters in corolla, anthers and pollen. Plant Mol. Biol. 12:539-551.

Whitehead, C.S., D.W. Fujino, and M.S. Reid. 1983. Identification of the ethylene precursor, 1-aminocyclopropane-1-carboxylic acid (ACC) in pollen. Sci. Hortic. 21:291-297.

Wing, R.A., J. Yamaguchi, S.K. Larabell, V.M. Ursin, and S. McCormick. 1989. Molecular and genetic characterization of two pollen expressed genes that have sequence similarity to pectate lyases of the plant pathogen Erwinia.. Plant Mol. Biol. 14:17-28.

Yip, W-K., J.G. Dong, J.W. Kenny, G.A. Thompson, and S.F. Yang. 1990. Characterization and sequencing of the active site of 1-aminocyclopropane-1-carboxylate synthase. Proc. Natl. Acad. Sci. USA. 87:79307934.

Yip, W-K., T. Moore, and S.F. Yang. 1992. Differential accumulation of transcripts for four tomato 1-aminocyclopropane-1-carboxylate synthase homologs under various conditions. Proc. Natl. Acad. Sci. USA 89: 2475-2479.

Zarembenski, T.I., A. Theologis. 1994. Ethylene biosynthesis and action: a case of conservation. Plant Mol. Biol. 26:1579-1597. 